\title{
P88 Improvement in Functional Capacity with Spironolactone Masks the Treatment Effect on Exercise Blood Pressure
}

\author{
Myles Moore ${ }^{1}$, Martin Schultz ${ }^{1}$, James Hare ${ }^{2}$, Thomas Marwick², James Sharman ${ }^{1}$ \\ ${ }^{1}$ Menzies Institute for Medical Research, University of Tasmania, Hobart, Australia \\ ${ }^{2}$ Baker Heart and Diabetes Institute and Department of Cardiology, The Alfred Hospital, Melbourne, Australia
}

\section{ABSTRACT}

Background: A hypertensive response to submaximal exercise is associated with cardiovascular disease but may be influenced by functional capacity. Spironolactone may improve functional capacity, which could mask treatment effects on exercise blood pressure (BP). This study sought to examine this hypothesis.

Methods: This was a retrospective analysis of clinical trial data in 102 participants ( $54 \pm 9$ years; $52 \%$ male) with a hypertensive $\mathrm{BP}$ response to peak exercise (systolic $\mathrm{BP} \geq 210 \mathrm{mmHg}$ in men; $\geq 190 \mathrm{mmHg}$ in women) who were randomised to 3-months spironolactone $25 \mathrm{mg}$ daily $(n=53)$ or placebo control $(n=49)$. Submaximal exercise BP was measured during fixed low-intensity cycling (50-70\% maximal age-predicted heart rate). Functional capacity was measured as maximal oxygen capacity obtained during a separate maximal treadmill exercise test.

Results: Spironolactone improved submaximal exercise systolic BP with a small effect size compared to placebo ( $-4 \pm 16$ vs $2 \pm 15 \mathrm{mmHg}, p=0.08$, Cohen's $d=0.35)$, but also functional capacity with a small effect size $(0.64 \pm 5.10 \mathrm{vs}-1.43 \pm$ $5.04 \mathrm{ml} / \mathrm{kg} / \mathrm{min}, p=0.06$, Cohen's $d=0.41)$. However, when the change in submaximal exercise systolic BP was expressed relative to the change in functional capacity, there was a significant decrease with spironolactone compared to placebo $(-0.3 \pm 1.1$ vs $0.3 \pm 1.1 \mathrm{mmHg} / \mathrm{ml} \cdot \mathrm{kg} \cdot \mathrm{min}^{-1}, p=0.01$, Cohen's $d=0.54$ ).

Conclusion: Spironolactone may reduce submaximal exercise BP, but its full treatment effects may be hidden by increased functional capacity. A change in exercise BP should be interpreted according to any change in functional capacity.

(c) 2019 Association for Research into Arterial Structure and Physiology. Publishing services by Atlantis Press International B.V This is an open access article distributed under the CC BY-NC 4.0 license (http://creativecommons.org/licenses/by-nc/4.0/). 